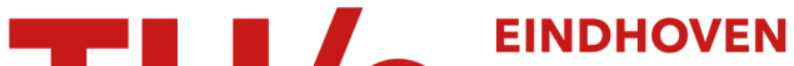 UNIVERSITY OF TECHNOLOGY
}

\section{Data-aided vs. blind single-carrier coherent receivers}

\section{Citation for published version (APA):}

Kuschnerov, M., Piyawanno, K., Spinnler, B., Kainzmaier, P., Alfiad, M. S., Napoli, A., \& Lankl, B. (2010). Dataaided vs. blind single-carrier coherent receivers. In Proceedings of the 2010 Conference on Optical Fiber Communication (OFC), collocated National Fiber Optic Engineers Conference (OFC/NFOEC), 21-25 march 2010, San Diego, California (pp. OMR5-1/3). Institute of Electrical and Electronics Engineers.

Document status and date:

Published: 01/01/2010

\section{Document Version:}

Publisher's PDF, also known as Version of Record (includes final page, issue and volume numbers)

\section{Please check the document version of this publication:}

- A submitted manuscript is the version of the article upon submission and before peer-review. There can be important differences between the submitted version and the official published version of record. People interested in the research are advised to contact the author for the final version of the publication, or visit the $\mathrm{DOI}$ to the publisher's website.

- The final author version and the galley proof are versions of the publication after peer review.

- The final published version features the final layout of the paper including the volume, issue and page numbers.

Link to publication

\section{General rights}

Copyright and moral rights for the publications made accessible in the public portal are retained by the authors and/or other copyright owners and it is a condition of accessing publications that users recognise and abide by the legal requirements associated with these rights.

- Users may download and print one copy of any publication from the public portal for the purpose of private study or research.

- You may not further distribute the material or use it for any profit-making activity or commercial gain

- You may freely distribute the URL identifying the publication in the public portal.

If the publication is distributed under the terms of Article 25fa of the Dutch Copyright Act, indicated by the "Taverne" license above, please follow below link for the End User Agreement:

www.tue.nl/taverne

Take down policy

If you believe that this document breaches copyright please contact us at:

openaccess@tue.nl

providing details and we will investigate your claim. 


\title{
Data-Aided vs. Blind Single-Carrier Coherent Receivers
}

\author{
M. Kuschnerov ${ }^{1}$, K. Piyawanno ${ }^{1}$, B. Spinnler ${ }^{2}$, P. Kainzmaier ${ }^{2}$, \\ M.S. Alfiad ${ }^{3}$, A. Napoli ${ }^{2}$, B. Lankl ${ }^{1}$ \\ ${ }^{1}$ University of the Federal Armed Forces Munich, Institute for Communications Engineering \\ Neubiberg, Germany \\ ${ }^{2}$ Nokia Siemens Networks GmbH \& Co. KG, Munich, Germany \\ ${ }^{3}$ COBRA institute, Eindhoven University of Technology, The Netherlands \\ maxim.kuschnerov@unibw.de,m.s.alfiad@tue.nl,bernhard.spinnler@nsn.com
}

\begin{abstract}
Blind and data-aided single-carrier receivers are discussed for high-speed optical coherent receivers. Equalization concepts are presented and evaluated regarding the implementation complexity and overhead for time-domain and frequency-domain equalization techniques.

(c) 2010 Optical Society of America

OCIS codes: (060.1660) Coherent communications; (060.2360) Fiber optics links and subsystems
\end{abstract}

\section{Introduction}

The characteristics of linear effects in the fiber optic link differ from typical time-varying wireless channels. Although the fiber channel can be considered mostly time-invariant, coherent receivers should be able to track mechanicallyinduced polarization changes [1] with a reasonable penalty. Dominant linear effects such as chromatic dispersion (CD) and polarization-mode dispersion (PMD) can be fully compensated using linear filters due to their all-pass character. Even in presence of polarization-dependent loss (PDL), it can be shown that maximum-likelihood receivers do not outperform linear receivers for worst-case PDL. Thus, the problem of equalization in the fiber is of greater simplicity than in frequency-selective wireless fading channels. The drawbacks of the fiber channel are the relatively high local oscillator phase noise, constraints due to signal processing parallelization, and fiber nonlinearities.

Although blind receivers have been a popular choice for coherent polarization-multiplexed (PolMux) QPSK [2], blind and data-aided algorithms have to be reevaluated in view of next-generation higher-order modulation formats for single-carrier (SC) receivers, especially since coherent optical orthogonal frequency division multiplex (CO-OFDM) experiments predominantly use data-aided methods [3].

\section{Blind Source Separation}

Blind receivers have been frequently used in coherent fiber optic transmission experiments and offer some advantages. They do not require additional overhead, can reasonably track the fastest gradients in the fiber channel and are a good fit for the simple case of PolMux-QPSK, when using the constant-modulus algorithm (CMA) or the $m^{\text {th }}$ power carrier phase estimation [2]. In terms of equalization, the minimum mean square error (MMSE) solution is optimal for linear filters and can be computed using the least-mean square (LMS) stochastic gradient algorithm [4]. In the fiber optic channel, the CMA equalizer converges to the LMS solution and is typically used for channel acquisition. A receiver block diagram is given in Fig. 1 [5]. Here, the bulk of the chromatic dispersion is compensated in the frequency domain equalizer (FDE). The finite-impulse response (FIR) filter compensates for residual linear distortion and demultiplexes the two polarizations using time-domain equalization (TDE). Finally, the carrier phase error is corrected in the feed forward carrier phase estimation (FF-CPE).

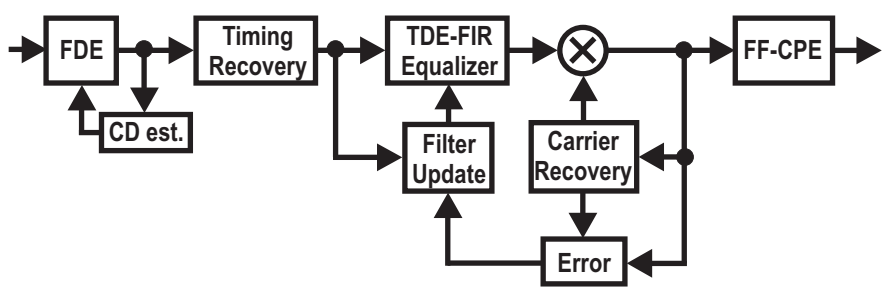

Fig. 1. Block diagram of the signal processing components in a blind coherent receiver.

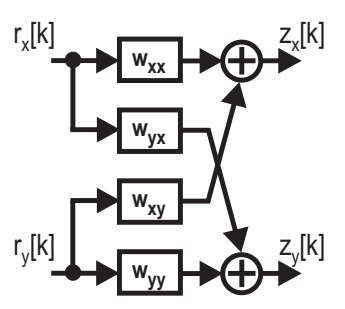

Fig. 2. FIR butterfly filter used for polarization demultiplexing.

Translating the CMA from to a multiple-input multiple-output (MIMO) equalizer solution results in the possibility of degenerate one-to-many output solutions, especially in the presence of PDL. In [6], a flexible blind source separation algorithm using independent component analysis (ICA) was presented that works as an extension of the CMA. The 
cost function is given by

$$
J(\boldsymbol{w})=E\left(\sum_{i=1}^{2}\left(\left|z_{i}[k]\right|^{2}-R_{2}\right)^{2}+2 \sum_{l, m=1, l \neq m}^{2} \sum_{\xi=\xi_{1}}^{\xi_{2}}\left|\rho_{l m}[\xi]\right|^{2}, \quad \rho_{l m}[\xi]=E\left(z_{l}[k] z_{m}^{*}[k-\xi]\right),\right.
$$

where $E$ is the expectation value, $\rho_{l m}(\xi)$ the cross-correlation function between polarization 1 and $\mathrm{m}$, and $\xi_{1}, \xi_{2}$ are integers that depend on the channel delay spread. Computing the derivative of the cost function with respect to the equalizer taps, a stochastic gradient update can be formulated that minimizes the cross-correlation between the two polarizations. The instantaneous expectation value of the cross-correlation coefficient $\rho$ and the error $\eta$ for the $\xi^{t h}$ tap are given by

$$
\rho_{l m}^{(k)}[\xi]=(1-\epsilon) \cdot \rho_{l m}^{(k-1)}[\xi]+\epsilon \cdot z_{l}[k] \cdot z_{m}^{*}[k-\xi], \quad \eta_{l}^{(k)}=-\sum_{\xi=0}^{(N-1) / 2} \rho_{l m}^{(k)}[\xi] \cdot z_{m}[k-\xi],
$$

where $\epsilon$ is a forgetting factor and $N$ the odd number of taps of the T/2-spaced filter. The tap updates are then given by

$$
w_{l m}^{(k)}[n]=w_{l m}^{(k-1)}[n]+\mu \cdot \eta_{l}^{(k)} \cdot r_{m}^{*}[k-n] .
$$

This extension makes it possible to equalize and demultiplex the signal even in presence of severe CD, PMD and PDL [5]. Although the update algorithm can be further simplified in the implementation, the additional complexity is evident as shown in Fig. 3, where it is also compared to the data-aided version of the more complex MMSE-equalizer.

For higher-order modulation formats, in general the CMA has worse tracking abilities than the LMS due to the residual error in the estimation. On the other hand, the LMS requires an additional feedback loop in order to correct the carrier phase, which leads to a significantly reduced response bandwidth due to the inherently necessary parallelization and processing delay. The tracking performance of the two update algorithms is evaluated for $112 \mathrm{~Gb} / \mathrm{s}$ PolMux 16QAM in the signum update version in Fig. 4 with a transmitter and receiver local oscillator bandwidth of $100 \mathrm{kHz}$.

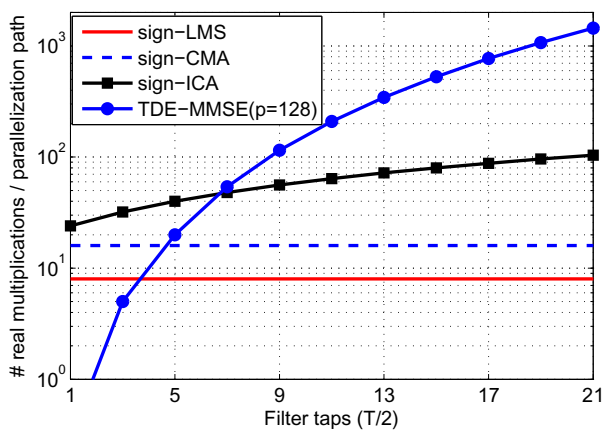

Fig. 3. Filter update complexity for various adaptation algorithms. Simplified version of the ICA with signum update is used.

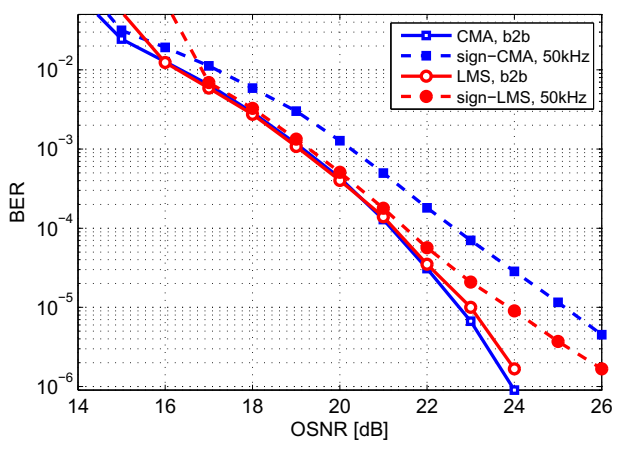

Fig. 4. Tracking performance of the CMA and LMS for $112 \mathrm{Gbit} / \mathrm{s}$ PolMux-16QAM for a polarization rotation of 50kHz. Parallelization degree $=64$ with typical feedback delays.

While the LMS outperforms the CMA in the parallelized implementation, it can greatly deteriorate in presence higher laser phase noise or sudden frequency jumps. Moreover, the second-degree phase-locked loop (PLL) requires a precise initial estimation of the frequency offset, since it can only lock on to offsets of a few $\mathrm{MHz}$ in a parallelized implementation. In blind receivers, the frequency offset can e.g. be estimated using the symmetry of the signal spectrum [7]. However, unsymmetrical filters lead to an estimation bias, making only rough estimation possible. Differential $\mathrm{m}^{\text {th }}$-power algorithms [8] can also be used for initial frequency offset estimation, although their performance deteriorates for higher-order modulation and low signal-to-noise ratio (SNR).

In general, blind algorithms do not scale well with higher-order modulation. The channel acquisition time increases with lower gradient tracking speeds. For low SNRs, blind estimator performance is deteriorated disproportionally. In addition, parallelized feedback loops become unstable for low SNR, as it can be seen in Fig. 4. Finally, the high complexity that is necessary for a fully flexible blind equalizer is one of the biggest drawbacks compared to data-aided algorithms that will be discussed in the next section.

\section{Data-Aided Receivers}

Data-aided receivers can be attractive for fiber optic applications due to their fast acquisition and lower complexity, and have been extensively used in coherent optical orthogonal frequency division multiplexing (OFDM) [3]. However, it can also be argued that there is no need for data-aided channel acquisition due to the rather static channel. 
If time-domain equalization (TDE) is used, the direct MMSE computation of the equalizer taps is in general not viable due to the complexity of the matrix inversion, as shown in Fig. 3. Though much slower in its acquisition time, the LMS algorithm has the least complexity for adapting equalizer taps. Several drawbacks arise when using dataaided LMS. The equalizer taps can only be adapted using several subsequent headers, requiring prior carrier phase synchronization. Common methods can be used for this purpose [10], while limiting the maximum block length [9]. Blind polarization and carrier phase tracking is still required, as these parameters can change within a data block.

Frequency-domain equalization (FDE) offers lower complexity compared to TDE at a certain filter length, which is why it is used for the compensation of chromatic dispersion in optically uncompensated links. If the filter is parallelized to a high degree, the break-even point for FDE is reached even earlier as seen in Fig. 5, making single-carrier frequency domain equalization (SC-FDE) attractive even for compensated links [11]. A fully data-aided based approach for SCFDE also eliminates the requirement for equalizer and carrier phase feedback loops. The limitation for SC-FDE is the signal overhead, which depends on the maximum tolerable channel gradient and the channel impulse response length as illustrated in Fig. 6 with constant amplitude zero autocorrelation (CAZAC) sequences used for training similar to [3]. For large values of dispersion, the equalization can be split up in two stages with blind CD compensation and a fully adaptive SC-FDE, similar to TDE in Fig. 1.

SC-FDE also offers the advantage of fast channel acquisition, since the computation of the MMSE equalizer solution requires mainly the inversion of several $2 \times 2$ matrices. A cyclic prefix is not necessarily required, as the signal can also be equalized using the overlap and save technique [4].

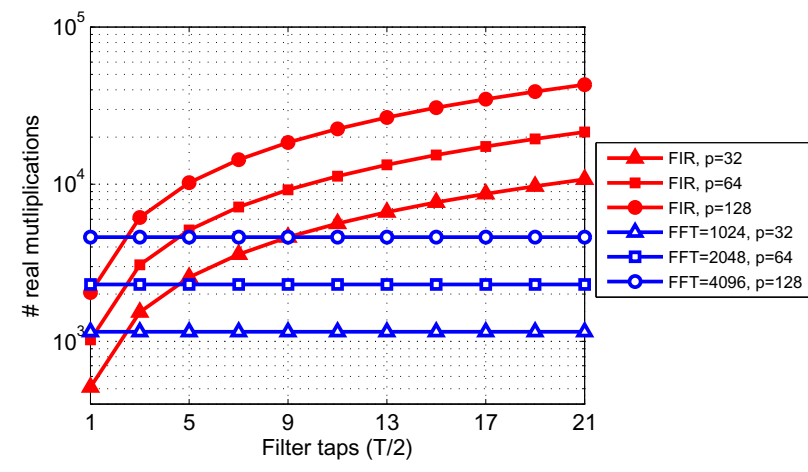

Fig. 5. Filtering complexity of time domain equalization compared with frequency domain equalization for varying degrees of parallelization.

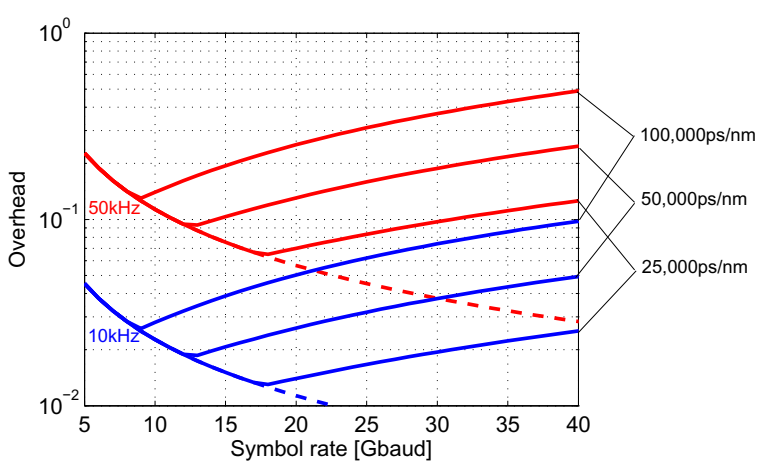

Fig. 6. Signal overhead for polarization rotation gradients of $10 \mathrm{kHz}$, $50 \mathrm{kHz}$ if no blind channel tracking is used for a single stage FDE.

\section{Conclusion}

Despite a higher signal overhead, data-aided receiver algorithms lead to simple and scalable receiver design. Similar to OFDM, training sequences make fast channel acquisition possible, which will become important in future optically switched networks. For parallelized processing, fully adaptive frequency domain equalization offers an advantage over time-domain filters even for a small channel memory. For time-domain equalization with preceding blind CD compensation, the overhead can be kept to 3-5\%. The overhead in frequency-domain equalization receivers can be larger and is dictated by the maximum polarization rotation gradient.

\section{References}

[1] P. M. Krummrich and K. Kotten, "Extremely fast (microsecond timescale) polarization changes in high speed long haul WDM transmission system", in the proceedings of OFC 2004, Los Angeles, CA, paper FI3.

[2] C.R.S. Fludger, T. Duthel, D. van den Borne, C. Schulien, E.-D. Schmidt, T. Wuth, J. Geyer, E. De Man, G.-D. Khoe, H. de Waardt, "Coherent Equalization and POLMUX-RZ-DQPSK for Robust 100-GE Transmission", J. of Lightw. Techn., vol. 26, no. 1, Jan. 2008 , pp. 64.

[3] W. Shieh, X. Yi, Y. Ma, Q. Yang, "Coherent optical OFDM: has its time come?", J. of Opt. Networking, Vol. 7, No. 3, pp. 234, March 2008.

[4] N. Benvenuto, G. Cherubini, "Algorithms for Communications Systems and their Applications", John Wiley \& Sons, Ltd, 2002.

[5] M. Kuschnerov, F.N. Hauske, K. Piyawanno, B. Spinnler, M. Alfiad, A. Napoli, B. Lankl, "DSP for Coherent Single-Carrier Receivers", J. of Lightw. Techn., Vol. 27, No. 16, pp. 3614.

[6] A.J. Paulraj, C.B. Papadias, "Space-time processing for wireless communications", IEEE Sign. Proc. Mag., vol. 14, no. 6, Nov. 1997, pp. 49.

[7] K. Piyawanno, M. Kuschnerov, B. Spinnler, B. Lankl, "Fast and Accurate Automatic Frequency Control for Coherent Receivers", Proc. ECOC 2008, Vienna.

[8] H. Meyr, M. Moeneclaey, S.A. Fechtel, "Digital Communication Receivers", John Wiley \& Sons, Inc., 1998.

[9] M. Kuschnerov, K. Piyawanno, E. De Man, M. Chouayakh, B. Spinnler, M. Alfiad, A. Napoli, B. Lankl, "Data-Aided Single Carrier Coherent Receivers", Proc. 22nd Annual Photonics Society Meeting, Antalya, 2009.

[10] T.M. Schmidl, D.C. Cox, "Robust Frequency and Timing Synchronization for OFDM", Trans. Comm., Vol. 45, No. 12, pp. 1613 , Dec. 1997.

[11] D. Falconer, S.L. Ariyavisitakul, A. Benyamin-Seeyar, B. Eidson, "Frequency domain equalization for single-carrier broadband wireless systems", IEEE Commun. Mag., vol. 40, n0. 4, pp. 58-66, Apr. 2002. 